\title{
Left ventricular function at rest and during exercise in acute hypothyroidism
}

\author{
SIEGFRIED WIESHAMMER, * FRITZ S KECK, * JOSEF WAITZINGER, $\dagger$ \\ JOACHIM KOHLER, * WILLIE ADAM,† MARTIN STAUCH, * \\ ERNST F PFEIFFER *
}

From the ${ }^{\star}$ Departments of Internal Medicine and $\uparrow$ Nuclear Medicine, University of Ulm Medical Centre, Ulm, Federal Republic of Germany

SUMMARY The effect of hypothyroidism on left ventricular function at rest and during exercise was studied in nine patients without demonstrable cardiovascular disease who had had total thyroidectomy and ablative radioiodine treatment for thyroid cancer. Radionuclide ventriculography and simultaneous right heart catheterisation were performed while the patientswere hypothyroid two weeks after stopping triiodothyronine treatment (to permit routine $\oint^{D}$ screening for metastases) and while they were euthyroid on thyroxine replacement treatment ${ }_{\bar{\Phi}}^{\circ}$

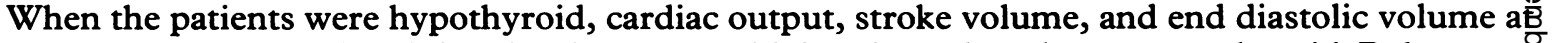
rest were all lower and peripheral resistance was higher than when they were euthyroid. Pulmonary capillary wedge pressure, right atrial pressure, heart rate, left ventricular ejection fraction, and the systolic pressure:volume relation of the left ventricle, which was used as an estimate of thछ contractile state, were not significantly different when the patients were hypothyroid or euthyroid During exercise, heart rate, cardiac output, end diastolic volume, and stroke volume were highe? when the patients were euthyroid than when they were hypothyroid. Again, pulmonary capillar wedge pressure, ejection fraction, and the systolic pressure:volume relation were similar in both thyroid states.

The data suggest that the alterations in cardiac performance seen in short term hypothyroidisn $\vec{\delta}$ are primarily related to changes in loading conditions and exercise heart rate; they do not sugges that acute thyroid hormone deficiency has a major effect on the contractile properties of the myocardium.

Thyroid hormone deficiency is known to affect the heart. ${ }^{1-3}$ Although exercise intolerance is a classic feature of hypothyroidism, most studies have focused on the contractile function of the heart at rest $^{4-6}$ and little attention has been paid to the performance of the left ventricle during exercise.

Some radionuclide studies assessed the response of the ejection fraction to stress in hypothyroid patients. ${ }^{7-9}$ The ejection fraction is widely accepted as a useful measure of ventricular performance ${ }^{10}$ but it has limitations. Because it is the ratio of two physiological variables the size of the left ventricular chamber can change considerably without causing a significant change in ejection fraction. So the

Requests for reprints to Dr Siegfried Wieshammer, Cardiology Section, Department of Internal Medicine, University of Ulm, Steinhövelstraße 9, D-7900 Ulm, Federal Republic of Germany.

Accepted for publication 9 November 1987 haemodynamic consequences of hypothyroidism are only incompletely evaluated by the response of the ejection fraction to stress, and for a more compreheng sive assessment left ventricular volumes and pres sures must be measured. More importantly, the ejection fraction is dependent not only on the intrin sic contractile state of the heart but also on the preload and afterload. ${ }^{11}$ Changes in loading condi tions seem to be especially important when thyroiđ function is abnormal ${ }^{12}$ and, therefore, it is unreliabls to infer the level of contractile activity from the change in ejection fraction when the euthyroid stato is restored.

We used radionuclide angiography and right hear catheterisation to assess the response of the lefe ventricle at rest and during exercise to severe short term hypothyroidism. We attempted to distinguis $\overline{\mathrm{B}}$ between the effects on the heart's loading conditions and the effects on contractility. 


\section{Patients and methods}

\section{STUDY GROUP}

We studied five women and four men aged 18 to 56 years (mean (SD) 43 (13) years). The patients had undergone total thyroidectomy and ablative radioiodine treatment for thyroid cancer 22 to 89 months (63 (23) months) before the current study and they were free of metastases at regular follow up examinations. None of the patients was hypertensive or had evidence of cardiovascular disease on the basis of history, clinical examination, chest radiographs, resting electrocardiogram, and exercise electrocardiogram. When they were hypothyroid none of the patients had a pericardial effusion shown by echocardiography. Except for thyroxine, no patient was taking any drugs at the time of cardiac assessment. The purpose of the study was fully explained to each patient and their informed written consent was obtained.

All patients were studied at rest and during supine bicycle exercise when they were euthyroid by clinical and laboratory standards and when they were hypothyroid after replacement treatment with thyroid hormones had been stopped to permit a routine iodine-131 total body scan for metastases.

In four patients the initial study was performed while they were taking thyroxine and were euthyroid. Then thyroxine was replaced by triiodothyronine five weeks before the second study, which was carried out two weeks after triiodothyronine was stopped. The remaining five patients were first studied when they were hypothyroid after long term replacement treatment with thyroxine had been stopped. After the study was completed, treatment with thyroxine was re-started at an initial daily dose of $0.9 \mathrm{nmol} / \mathrm{kg}$ body weight. The dosage was increased by increments of $0.9 \mathrm{nmol} / \mathrm{kg}$ body weight every five weeks until the thyrotropin releasing hormone test was normal. The patients were restudied when they had been clinically and biochemically euthyroid for at least six weeks.

\section{ASSAYS}

Serum concentrations of thyroxine, triiodothyronine, and thyrotropin were measured by commercial radioimmunoassays (T4 and T3 RIA kits from Bayer AG, Leverkusen, West Germany, and TSH IRMA from Behringwerke AG, Marburg, West Germany). The sensitivity was $6.4 \mathrm{nmol} / 1$ for thyroxine, $0.3 \mathrm{nmol} / 1$ for triiodothyronine, and $0.02 \mathrm{mU} / 1$ for thyrotropin. The uptakes of thyroxine and triiodothyronine were measured to detect any alterations in hormone binding and the free thyroxine equivalent and the free triiodothyronine equivalent were calculated. All samples were analysed in duplicate in a single radioimmunoassay run. In this laboratory, the normal ranges for serum concentrations of thyroxine and triiodothyronine are 51.5$154.4 \mathrm{nmol} / 1$ and $1 \cdot 23-2 \cdot 76 \mathrm{nmol} / 1$ respectively. The upper limit of normal for basal thyrotropin is $4 \mathrm{mU} / 1$ and the normal range of thyrotropin 20 minutes after intravenous administration of $200 \mu \mathrm{g}$ of thyrotropin releasing hormone is $2-30 \mathrm{mU} / 1$.

\section{RADIONUCLIDE AND CATHETERISATION TECHNIQUES}

The baseline heart rate was recorded one hour before the study and the change in heart rate after cardiac instrumentation was regarded as an index of the individual anxiety level prompted by cardiac catheterisation. In the nuclear imaging laboratory a Swan Ganz 7F thermodilution catheter was passed to the pulmonary artery via an antecubital vein under continuous pressure monitoring. Right atrial and pulmonary artery pressures were measured with a $\mathbf{P}$ 23 Statham strain gauge from a reference level $5 \mathrm{~cm}$ below the sternal angle. Blood pressure was measured by a standard cuff sphygmomanometer. The electrocardiogram was recorded throughout the study. Cardiac output was measured in triplicate by the thermodilution technique. Saline injections were started at end exhalation. ${ }^{13}$

The patients were injected with $20 \mathrm{mCi}(740 \mathrm{MBq}$ ) of technetium-99m for in vivo labelling of red blood cells and were imaged in the modified left anterior oblique position. The left ventricular ejection fraction was measured from the background-corrected time activity curve with a fully automated edge detection algorithm. Regional wall motion was assessed by the Fourier analysis of radionuclide ventriculograms. These radionuclide techniques have been described earlier. ${ }^{14}$

The patients were already familiar with supine exercise from a previous practice session. ${ }^{15}$ After acquisition of haemodynamic and radionuclide data at rest, single level supine exercise was carried out at a workload of $100 \mathrm{~W}$ in six patients. In two patients who were limited by severe muscle weakness when hypothyroid, the workload was reduced to $75 \mathrm{~W}$ in both studies and one subject was exercised at $50 \mathrm{~W}$. Imaging started four minutes after the start of the stress test to ensure a steady state. The haemodynamic measurements were made during the sixth minute of exercise.

DERIVED HAEMODYNAMIC VARIABLES

Derived haemodynamic variables were calculated as follows:

Left ventricular end diastolic volume $(\mathrm{ml})=$ stroke volume:ejection fraction 
Systemic vascular resistance $\left[\right.$ dyn.s. $\left.\mathrm{cm}^{-5}\right]=80 \times$ (mean arterial pressure-mean right atrial pressure) $\div$ cardiac output.

The mean arterial pressure was calculated as the diastolic pressure plus one third of the pulse pressure. Systemic vascular resistance was not calculated for the exercise studies because we find that sphygmomanometric measurements of the exercise diastolic blood pressure are unreliable.

Left ventricular end systolic volume $(\mathrm{ml})=$ end diastolic volume - stroke volume.

Left ventricular systolic pressure:volume ratio $[\mathrm{mm} \mathrm{Hg} / \mathrm{ml}]=$ sphygmomanometric systolic blood pressure $\div$ left ventricular end systolic volume.

\section{STATISTICAL ANALYSIS}

Wilcoxon's test for paired observations was used for statistical analysis. All results are given as the mean (1 SD) unless stated otherwise. A probability value of $\mathrm{p}<0.05$ was regarded as statistically significant.

\section{Results}

\section{THYROID STUDIES}

Table 1 shows the biochemical data. The daily dose of thyroxine required for a normal thyrotropin releasing hormone test ranged from $97 \mathrm{nmol}$ to 322 nmol (mean 214 (71)).

\section{HAEMODYNAMIC DATA}

When the patients were euthyroid the haemodynamic and radionuclide measurements were consistently within normal limits. Standardisation of cardiac output and left ventricular volumes for body surface did not change the significance values of any data. Whether the patients were first studied when they were euthyroid or when they were hypothyroid had no discernible effect on the test outcomes. The heart rate an hour before the study was similar to that recorded upon completion of cardiac instrumentation in both euthyroid and hypothyroid patients, suggesting that the anxiety level associated with right heart catheterisation was low $(68(12) v 70$ (11) beats/ min and 81 (15) $v 80$ (14) beats/min respectively).

Table 1 Concentrations of serum thyroid hormones in nine athyreotic patients when hypothyroid and when euthyroid on thyroxine replacement

\begin{tabular}{llcc}
\hline & Hypothyroid & Euthyroid & Normal range \\
\hline Total T4 (nmol/1) & $8 \cdot 2(2.5)$ & $128.7(24.5)$ & $51.5-154.4$ \\
FT,E & $0 \quad(0)$ & $0.81(0.29)$ & $0.28-1.21$ \\
Total T3 (nmol/1) & $0.52(0.37)$ & $2.21(0.63)$ & $1.23-2.76$ \\
FT, E & $0.06(0.04)$ & $0.59(0.28)$ & $0.4-0.8$ \\
\hline
\end{tabular}

Values are mean (1 SD).

T4, thyroxine; FT ${ }_{4}$, free thyroxine equivalent; T3, triiodothyronine; $\mathrm{FT}_{3} \mathrm{E}$, free triiodothyronine equivalent.
Table 2 Haemodynamic and radionuclide data at rest in $\vec{c}$ nine athyreotic patients without demonstrable cardiovascular. disease when hypothyroid and when euthyroid on thyroxine $\stackrel{5}{\rightarrow}$ replacement

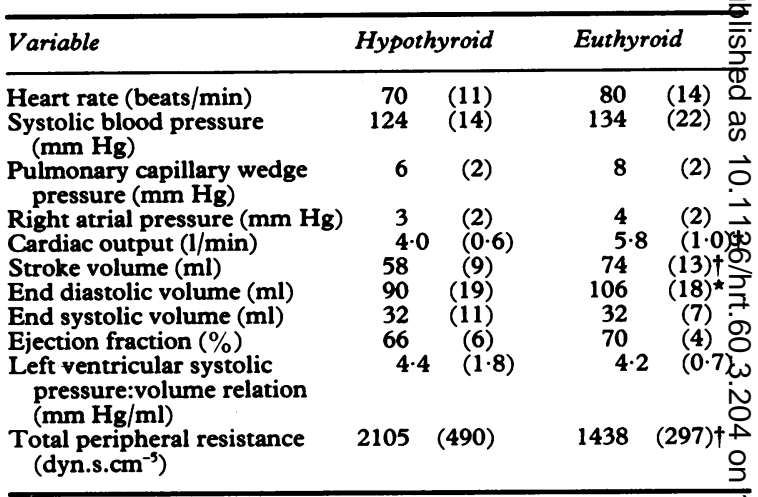

Values are mean (1 SD). Differences were analysed by thes Wilcoxon test for paired observations. ( ${ }^{\star} \mathrm{p}<0.05$; $+\mathrm{p}<0.01$.)

Table 2 summarises the haemodynamic an radionuclide data at rest. Resting hypothyroid and euthyroid values were similar for right atrial pressure

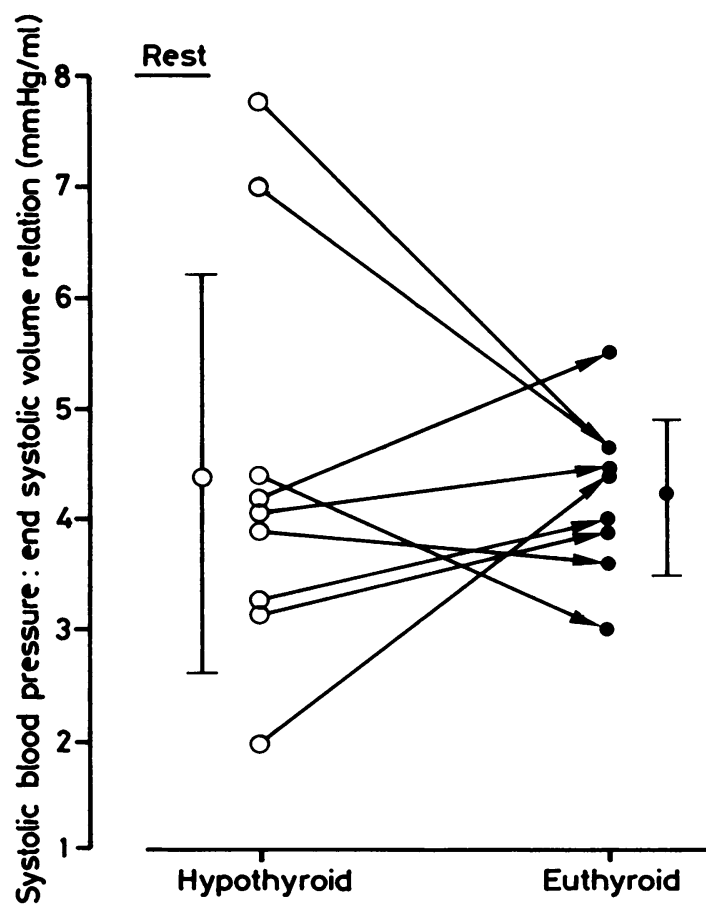

Fig 1 Individual and group mean values for the left ventricular systolic pressure:volume ratio in the hypothyroid (left) and in the euthyroid state (right) at rest. Overall, concentrations of thyroid hormones had no significant effect on this variable, which is used as an estimate of the contractile state of the left ventricle. 

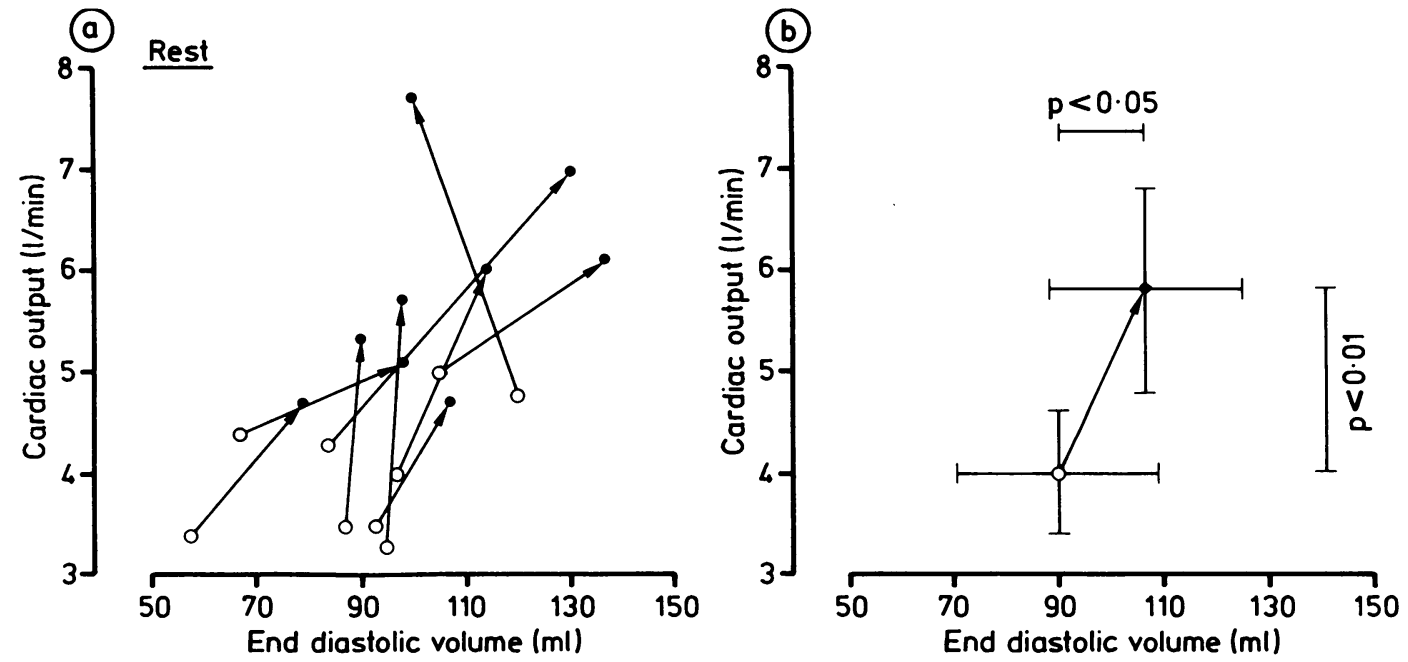

Fig 2 Relation between left ventricular end diastolic volume and cardiac output at rest in the hypothyroid ( $O$ ) and in the euthyroid (O) state. (a) The arrows joining two points represent changes in the value for individual patients. (b) The group mean (1SD) values. A change from the hypothyroid to the euthyroid state was accompanied by a significant increase in both cardiac output $(\Delta=45(19) \%, p<0.01)$ and left ventricular end diastolic volume $(\Delta=21(22) \%, p<0.05)$.

(3 (2) $v 4$ (2) $\mathrm{mm} \mathrm{Hg}$ ), pulmonary capillary wedge pressure $(6(2) v 8(2) \mathrm{mm} \mathrm{Hg}$ ), and mean arterial pressure $(105(10) v 106(15) \mathrm{mm} \mathrm{Hg})$. Similarly, hypothyroidism had no significant effect on end systolic volume (32 (11) $v 32(7) \mathrm{ml}$ ), on left ventricular ejection fraction (66 (6) $v 70(4) \%$ ), and on the systolic pressure:volume ratio of the left ventricle $(4.4(1.8) v 4.2(0.7) \mathrm{mm} \mathrm{Hg} / \mathrm{ml})($ fig 1$)$. The values for heart rate tended to be higher in euthyroid patients (70 (11) $v 80$ (14) beats $/ \mathrm{min}$ ) but this difference did not reach statistical significance. The ejection fraction was above $55 \%$ in all patients. Cardiac output $(4.0(0.6)$ v 5.8 (1.0) $1 / \mathrm{min}(\mathrm{p}<0.01)$ $\Delta=45(19) \%)$, stroke volume (58 (9) $\mathrm{ml} v 74$ (13) $\mathrm{ml}$

Table 3 Haemodynamic and radionuclide data during exercise in nine athyreotic patients without demonstrable cardiovascular disease when they were hypothyroid and when they were euthyroid on thyroxine replacement

\begin{tabular}{|c|c|c|}
\hline Variable & Hypothyroid & Euthyroid \\
\hline $\begin{array}{l}\text { Heart rate (beats/min) } \\
\text { Systolic blood pressure } \\
(\mathrm{mm} \mathrm{Hg})\end{array}$ & $\begin{array}{ll}120 & (18) \\
176 & (17)\end{array}$ & $\begin{array}{ll}137 & (19) \ddagger \\
177 & (19)\end{array}$ \\
\hline $\begin{array}{l}\text { Pulmonary capillary wedge } \\
\text { pressure }(\mathrm{mm} \mathbf{H g})\end{array}$ & $15 \quad(4)$ & $17 \quad$ (3) \\
\hline $\begin{array}{l}\text { Cardiac output }(\mathrm{l} / \mathrm{min}) \\
\text { Stroke volume }(\mathrm{ml}) \\
\text { End diastolic volume }(\mathrm{ml}) \\
\text { End systolic volume }(\mathrm{ml}) \\
\text { Ejection fraction }(\%) \\
\text { Left ventricular systolic } \\
\text { pressure:volume relation } \\
\text { (mm } \mathbf{H g} / \mathrm{ml})\end{array}$ & $\begin{aligned} 10 \cdot 1 & (1 \cdot 6) \\
86 & (16) \\
113 & (17) \\
28 & (8) \\
75 & (8) \\
7 \cdot 2 & (3 \cdot 5)\end{aligned}$ & $\begin{aligned} 13 \cdot 2 & (2 \cdot 0)^{\star} \\
99 & (21) \dagger \\
125 & (18) \ddagger \\
27 & (7) \\
78 & (7) \\
7 \cdot 0 & (2 \cdot 4)\end{aligned}$ \\
\hline
\end{tabular}

Values are mean (1 SD). Differences were analysed by the Wilcoxon test for paired observations. ${ }^{\star} \mathrm{p}<0.01$; $\nmid \mathrm{p}<0.05 ; \neq \mathrm{p}<$ 0.02 .
( $\mathrm{p}<0.01) \Delta=27(13) \%$ ), and end diastolic volume (90 (19) $\mathrm{ml} v 106(18) \mathrm{ml}(\mathrm{p}<0.05) \Delta=21(22) \%)$ were all lower when the patients were hypothyroid. Figure 2 shows the individual changes in cardiac output and the corresponding changes in end diastolic volume; individual haemodynamic responses to thyroid hormone deficiency were uniform. When a patient was hypothyroid, cardiac output was always lower and end diastolic volume was smaller in all but one case. Total peripheral resistance decreased substantially when the patients became euthyroid (2105 (490) v 1438 (297) dyn.s. $\mathrm{cm}^{-5}(\mathrm{p}<0.01)$ $\Delta=31(12) \%)$.

Table 3 shows the haemodynamic data measured during exercise. The values for systolic blood pressure and left ventricular end systolic volume were not significantly different during hypothyroidism and euthyroidism (176 (17) $v 177$ (19) $\mathrm{mm} \mathrm{Hg}$ and 28 (8) $v 27$ (7) $\mathrm{ml}$ respectively). As a result, the left ventricular systolic pressure:volume ratio was not significantly affected by alterations in thyroid function (7.2 (3.5) $v 7.0(2.4) \mathrm{mm} \mathrm{Hg} / \mathrm{ml}$ ) (fig 3). The exercise ratio was above $4.0 \mathrm{~mm} \mathrm{Hg} / \mathrm{ml}$ in all patients. Pulmonary capillary wedge pressures increased with exercise to similar levels in both thyroid states (15 (4) $v 17$ (3) $\mathrm{mm} \mathrm{Hg}$ ) nor were there significant differences in left ventricular ejection fraction (75 (8) $v 78(7) \%)$. The heart rate achieved with exercise was significantly lower during hypothyroidism $(120$ (18) v 137 (19) beats $/ \mathrm{min}, \mathrm{p}<0.02)$. Cardiac output and stroke volume were also significantly lower during hypothyroidism (10.1 (1.6) $v$ $13.2(2.0) \mathrm{l} / \mathrm{min}(\mathrm{p}<0.01)$ and $86(16) v 99(21) \mathrm{ml}$ 
Wieshammer, Keck, Waitzinger, Kohler, Adam, Stauch, Pfeiffe

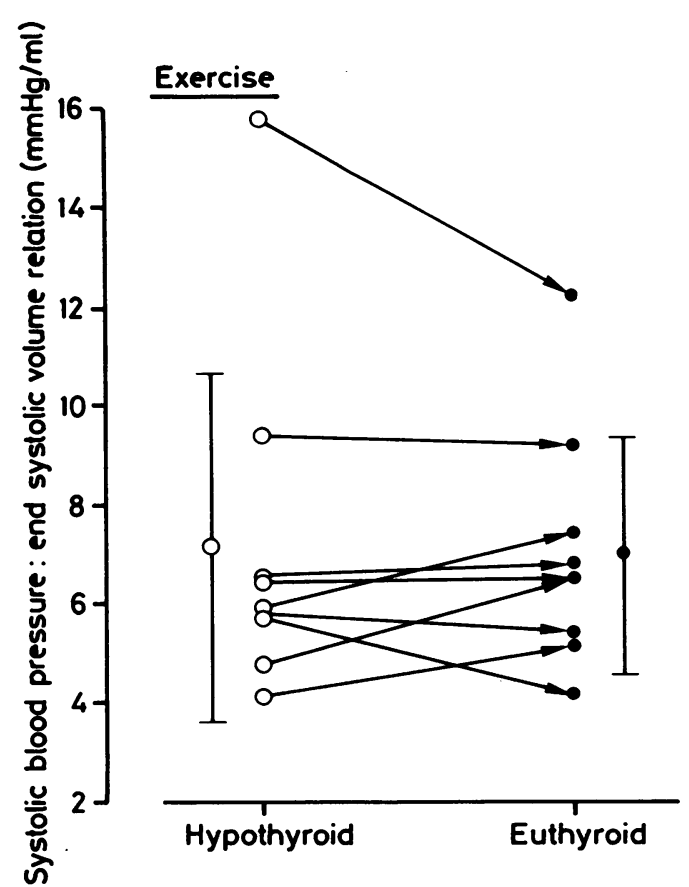

Fig 3 Individual and group mean values of the left ventricular systolic pressure:volume ratio in the hypothyroid (left) and in the euthyroid state (right) during exercise.

Thyroid function had no significant effect on this variable. $(\mathrm{p}<0.05)$ respectively). Thus at the same level of exercise, cardiac output was on average, 32 (15)\% higher and stroke volume was $15(13) \%$ higher when the patients were euthyroid than when they were hypothyroid. End diastolic volume too was $11(11)^{\circ} \%$ higher during euthyroidism (113 (17) $v 125$ (18) $\mathrm{mg}$ $(\mathrm{p}<0.02)$. Figure 4 shows the individual responses in cardiac output and end diastolic volume during exercise.

The increase in cardiac output with exercise was greater when the patients were euthyroid $(6 \cdot 1)(1 \cdot 7) \vec{w}$ $7.4(2.0) 1 / \mathrm{min}, \mathrm{p}<0.02)$. On average, stroke volums increased by $48(25) \%(p<0.01)$ above the restin values when patients were hypothyroid and by 36 $(28) \%(p<0.02)$ when they were euthyroid. Left ventricular end diastolic volume increased by $3 \hat{\circ}$ $(23) \%(p<0.01)$ with exercise in hypothyroid patients. Only a non-significant trend towards higher exercise values was found in the euthyroid state $(\Delta \overline{\bar{\sigma}}$ $20(24) \%, p<0 \cdot 10)$. End systolic volume did no change significantly from rest to exercise in either thyroid state. During euthyroidism, a total of six oug of the nine patients showed an increase in ejection fraction of at least $5 \%$ from rest to exercise, twg patients had increases of $<5 \%$, and one patient had $\&$ $1 \%$ decrease in ejection fraction with exercise. All patients attained an exercise ejection fraction of a least $60 \%$. In the hypothyroid state, seven patients had a significant increase in ejection fraction, on
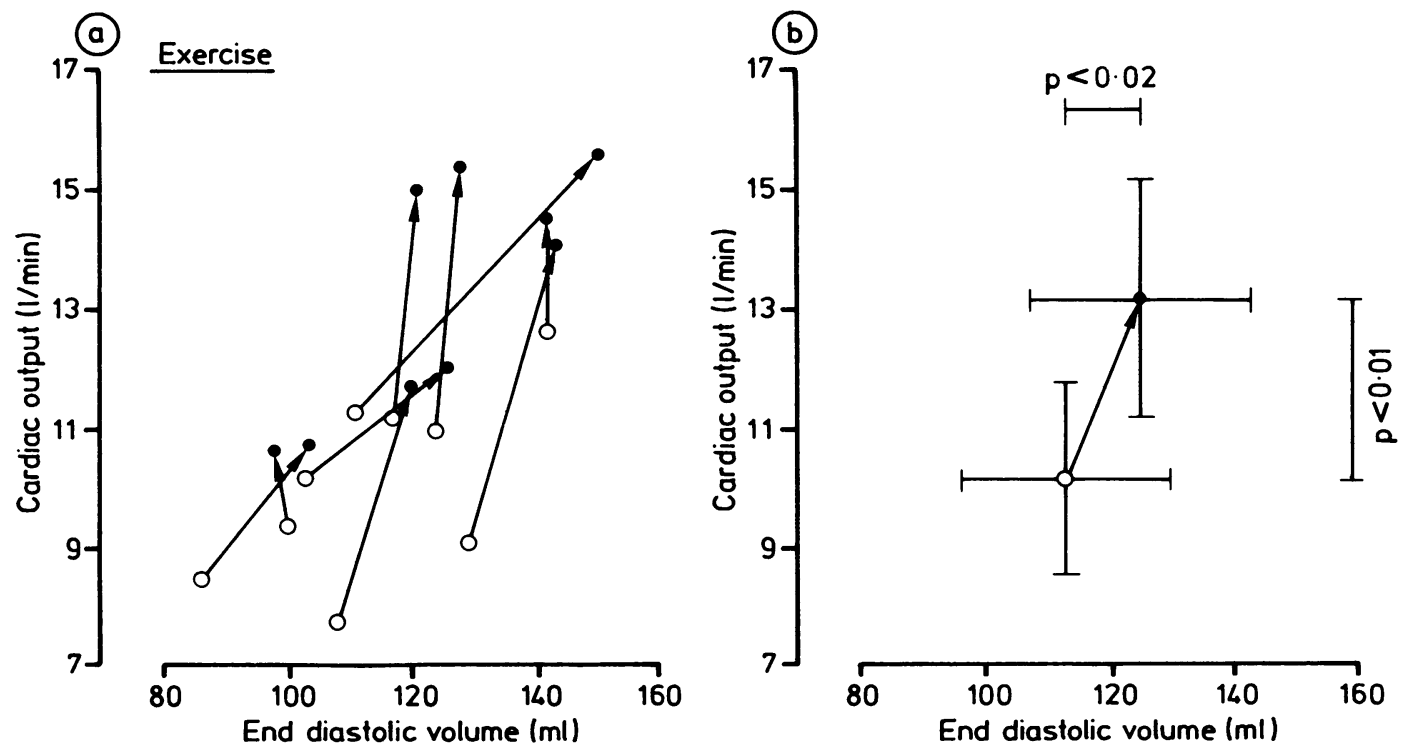

Fig 4 Relation of the left ventricular end diastolic volume with cardiac output during exercise in the hypothyroid (O) and in the euthyroid (O) state. (a) The arrows joining two points represent changes in the values for individual patients. (b) The group mean values. Left ventricular end diastolic volume and cardiac output were significantly higher when patients were euthyroid $(\Delta=11(11) \%,(p<0.02)$ and $\Delta=32$ (15) $\%,(p<0.01)$ respectively. 
patient had a $3 \%$ increase, and one had an $8 \%$ decrease in ejection fraction from rest to exercise. Regional wall motion was normal at rest and during exercise in all patients.

\section{Discussion}

The results of this study show that cardiac function at rest and during exercise was different in short term hypothyroidism and euthyroidism. The principal differences were decreases in end diastolic volume and stroke volume and a reduced exercise heart rate as the patients became hypothyroid. The absence of resting bradycardia in severe hypothyroidism is consistent with previous observations. ${ }^{1617}$ The systolic pressure:volume ratio of the left ventricle, which was used as an estimate of the inotropic state of the myocardium, was not significantly affected by thyroid hormone deficiency. Figure 3 shows that many patients had similar exercise ratios. These data suggest that the alterations in cardiac function seen in acute hypothyroidism are primarily related to changes in loading conditions and they do not support the concept that myocardial contractility is significantly depressed by short term thyroid hormone deficiency. This view was also supported by the finding that responses in pulmonary capillary wedge pressure to exercise were consistently within normal limits when patients were hypothyroid. ${ }^{18}$ Resting and exercise cardiac output are reduced in hypothyroidism. This was explained by the low metabolic rate of the peripheral tissues. ${ }^{19}$ Furthermore, the circulating blood volume is decreased in hypothyroidism..$^{20}$ These factors reduce venous return to the heart and, consequently, reduce the preload on the left ventricle. An echocardiographic study by Vora et al showed abnormal diastolic left ventricular function in hypothyroidism, ${ }^{16}$ and this may also contribute to the decrease in end diastolic volume.

In our study thyroid function changed quickly. We do not know whether the time-action curve of the effect of thyroid hormone on the contractile state is sufficiently shortlived to prevent a bias in the results. Chronic hypothyroidism causes profound abnormalities of cardiac structure. ${ }^{2122}$ Such alterations develop only after a longer period of thyroid hormone deficiency. So the results of this study are not applicable to longstanding hypothyroidism. Previous studies have also shown, however, that longterm hypothyroidism is significantly associated with large vessel coronary artery disease, which may also cause an abnormal haemodynamic state. ${ }^{2324} \mathrm{~A}$ recent study by Forfar et al reported a reduced left ventricular ejection fraction at rest and on exercise in subjects with longstanding hypothyroidism. ${ }^{7}$ Their patients had been hypothyroid for at least four months. A review of their data shows that one patient had chest pain compatible with angina and that two out of the eight patients had resting ejection fractions below $50 \%$ when euthyroid. It is conceivable that coronary artery disease contributed to the depressed left ventricular function in their patients whose mean age was 53. In contrast, our patients did not have demonstrable cardiovascular disease. They are a good study group for an analysis of the effects of acute thyroid hormone deficiency on cardiac haemodynamic function per se.

Fundamental to our argument that short term hypothyroidism does not significantly affect the contractile properties of the heart is the issue of whether the systolic pressure:volume ratio accurately reflects the inotropic state. Suga et al introduced the end systolic pressure:volume relation of the left ventricle as an estimate of myocardial contractility. ${ }^{25} 26$ Others have shown that the simple ratio between peak left ventricular systolic pressure and end systolic volume is also a sensitive indicator of left ventricular dysfunction. ${ }^{27} \mathrm{~A}$ study by Nivatpumin $e t$ al suggested that in human beings this ratio is independent of load and more sensitive than the ejection fraction in detecting an impaired left ventricular function. ${ }^{28}$ The use of systolic blood pressure, measured by sphygmomanometer, as an approximation of the left ventricular end systolic pressure is an obvious limitation of our study. An abnormal ratio between sphygmomanometric systolic blood pressure and end systolic volume was a sensitive indicator of an impaired left ventricular function at rest and during exercise, ${ }^{29}$ we regard this ratio as a useful estimate of the inotropic state.

Studies of isolated cardiac muscle preparations and of laboratory animals showed a negative inotropic effect of thyroid hormone deficiency and an enhanced inotropic state in hyperthyroidism..$^{30-32}$ Previous human studies that used serial measurements of the systolic time intervals ${ }^{5334}$ of the velocity of circumferential fibre shortening ${ }^{6}$ and of the radionuclide ejection fraction ${ }^{7}$ also suggested a reversible negative inotropic effect in chronic hypothyroidism and an enhanced contractile activity in hyperthyroidism. We do not question the validity of these studies and wish to re-emphasise that our patients cannot be used as a model of advanced primary hypothyroidism. Interpretation of these results in terms of contractile activity, however, should be done with caution. Isovolumetric and ejection phase indices are affected by several factors other than contractility and the serial evaluation of these indices can reliably indicate alterations in the inotropic state only if the loading conditions remain unchanged. The end diastolic volume may also be 
decreased in chronic hypothyroidism and this may, at least in part, account for the lengthening of the preejection period that is usually found in hypothyroidism without a major change in contractility. ${ }^{35} 36$ Similarly, the ejection fraction is intrinsically load dependent and declines with increasing afterload and decreasing preload, especially at smaller end diastolic volumes. ${ }^{11}$ Previous data on the preload dependence of the velocity of circumferential fibre shortening are inconsistent and, so this index may also be difficult to interpret. ${ }^{37} 38$ In summary, changes in isovolumetric or ejection phase indices may not reliably reflect changes in contractility in a patient who is becoming hypothyroid. In this context it is of interest that opposing changes in preload occur when a patient becomes hyperthyroid. Merillon et al found that the left ventricular end diastolic volume in hyperthyroid subjects was $34 \%$ larger than in matched euthyroid controls atrially paced to the same heart rate. ${ }^{39}$ The left ventricular end systolic pressure:volume ratios were similar in both groups and this suggests that alterations in contractility are of no great importance in hyperthyroidism.

Donaghue et al used a radionuclide method to study the effects of acute hypothyroidism on cardiac function. ${ }^{8}$ Their patients had been off triiodothyronine for 10 days and their mean age was 44 . Overall, the resting and exercise ejection fractions were similar in both thyroid states $(66(8) \% v 65(6) \%$ and $74(10) \% v 77(7) \%$, respectively), which accords with our findings. The ejection fraction did not rise significantly with exercise in four of the nine patients when they were hypothyroid whereas all of them had a significant increase when they were euthyroid. A recent radionuclide study by Smallridge et al assessed the rest and exercise left ventricular ejection fraction in four hypothyroid subjects aged 20 to 48 years before treatment and after restoration of euthyroidism. ${ }^{9}$ Thyroid deficiency had no significant effect on the resting and exercise ejection fraction in this young adult population. This is consistent with our data. Unfortunately, those authors did not state how long the patients had been hypothyroid before the study.

This study showed that there are significant alterations in loading conditions during short term hypothyroidism. There was no evidence of a major effect of acute thyroid hormone deficiency on the contractile state of the heart.

\section{References}

1 Zondek H. Das Myxödemherz. MMW 1918;65:1180-2.

2 Ohler WR, Abramson J. The heart in myxedema. Arch Intern Med 1934;53:165-87.
3 Altschule MD, Volk MC. The minute volume outpuE and the work of the heart in hypothyroidism. J Clin. Invest 1935;14:385-8.

4 Burckhardt D, Staub JJ, Kraenzlin M, Raeder E, Enged $\mathrm{U}$, Cloppenburg P. The systolic time intervals if thyroid dysfunction. Am Heart $J$ 1978;95:187-96.

5 Crowley WF, Ridgway EC, Bough EW, et al. Non invasive evaluation of cardiac function in hypothyroidism. Response to gradual thyroxine replacement. $N$ Engl J Med 1977;296:1-6.

6 Cohen MV, Schulman IC, Spenillo A, Surks MI: Effects of thyroid hormone on left ventricula function in patients treated for thyrotoxicosis. $\mathrm{Am}$ Cardiol 1981;48:33-8.

7 Forfar JC, Muir AL, Toft AD. Left ventriculas function in hypothyroidism. Responses to exercise and beta adrenoceptor blockade. Br Heart J 1982;48 278-84.

8 Donaghue $\mathrm{K}$, Hales I, Allwright $\mathrm{S}$, et al. Cardia $\frac{+}{\mathrm{S}}$ function in acute hypothyroidism. Eur $J$ Nucl Međ 1985;11:147-9.

9 Smallridge RC, Goldman $M H$, Raines $K$, Jones $S_{\Phi}^{C D}$ Van Nostrand D. Rest and exercise left ventricula ejection fraction before and after therapy in young adults with hyperthyroidism and hypothyroidism Am J Cardiol 1987;60:929-31.

10 Borer JS, Bacharach SL, Green MV, Kent KM Epstein SE, Johnston GS. Real-time radionuclid $\mathscr{E}_{0}^{\circ}$ cineangiography in the noninvasive evaluation of global and regional left ventricular function at reso and during exercise in patients with coronary-arter disease. N Engl J Med 1977;296:839-44.

11 Sonnenblick EH, Strobeck JE. Derived indexes of ventricular and myocardial function. $N$ Engl J Meg 1977;296:978-82.

12 Forfar JC, Caldwell GC. Hyperthyroid heart disease In: Toft $\mathrm{AD}$, ed. Clinics in endocrinology and metabol 3 ism. London, Philadelphia, Toronto: WB Saunders 1985:491-508.

13 Stevens JH, Raffin TA, Mihm FG, Rosenthal MHF Stetz CW. Thermodilution cardiac outpuw measurement. Effects of the respiratory cycle on its reproducibility. JAMA 1985;253:2240-2.

14 Adam WE, Tarkowska A, Bitter F, Stauch M, Geffer H. Equilibrium (gated) radionuclide ventriculo $\frac{\rho}{3}$ graphy. Cardiovasc Radiol 1979;2:161-73.

15 Spodick DH. First and second versus second and third exercise tests [Letter]. Circulation 1975;51:394.

16 Vora J, O'Malley BP, Petersen S, McCullough A Rosenthal FD, Barnett DB. Reversible abnormalitie of myocardial relaxation in hypothyroidism. $J$ Cli Endocrinol Metab 1985;61:269-72.

17 Hardisty CA, Naik DR, Munro DS. Pericardial effusion in hypothyroidism. Clin Endocrinol (Oxf) 1980, 13:349-54.

18 Ross J, Gault JH, Mason DT, Linhart JW, Braunwal@ E. Left ventricular performance during musculan exercise in patients with and without cardiac dys? function. Circulation 1966;34:597-608.

19 Graettinger JS, Muenster JJ, Checchia CS, Grissono RL, Campbell JA. A correlation of clinical an $\mathbb{D}$ hemodynamic studies in patients with hypo क्षे 
thyroidism. J Clin Invest 1958;37:502-10.

20 Gibson JG, Harris AW. Clinical studies of the blood volume. $\dot{V}$. Hyperthyroidism and myxedema. J Clin Invest 1939;18:59-65.

21 LaDue JS. Myxedema heart: a pathological and therapeutic study. Ann Intern Med 1943;18:332-44.

22 Brewer DB. Myxedema: an autopsy report with histochemical observations on the nature of the mucoid infiltrations. J Pathol Bacteriol 1951;63:503-12.

23 Vanhaelst L, Neve P, Chailly P, Bastenie PA. Coronary-artery disease in hypothyroidism. Lancet 1967;ii:800-2.

24 Steinberg AD. Myxedema and coronary artery disease-a comparative autopsy study. Ann Intern Med 1968;68:338-44.

25 Suga H, Sagawa K, Shoukas AA. Load independence of the instantaneous pressure-volume ratio of the canine left ventricle and effects of epinephrine and heart rate on the ratio. Circ Res 1973;32:314-22.

26 Suga H, Sagawa K. Instantaneous pressure-volume relationships and their ratio in the excised, supported canine left ventricle. Circ Res 1974;35:117-26.

27 Iskandrian AS, Hakki AH, Bemis CE, Kane SA, Boston $B$, Amenta A. Left ventricular end-systolic pressurevolume relation. A combined radionuclide and hemodynamic study. Am J Cardiol 1983;51:1057-61.

28 Nivatpumin T, Katz S, Scheuer J. Peak left ventricular systolic pressure/end-systolic volume ratio: a sensitive detector of left ventricular disease. Am J Cardiol 1979;43:969-74.

29 Dehmer GJ, Lewis SE, Hillis LD, Corbett J, Parkey RW, Willerson JT. Exercise-induced alterations in left ventricular volumes and the pressure-volume relationship: a sensitive indicator of left ventricular dysfunction in patients with coronary artery disease. Circulation 1981;63:1008-18.

30 Buccino RA, Spann JF, Pool PE, Sonnenblick EH,
Braunwald E. Influence of the thyroid state on the intrinsic contractile properties and energy stores of the myocardium. J Clin Invest 1967;46:1669-82.

31 Strauer BE, Schulze W. Experimental hypothyroidism: depression of myocardial contractile function and hemodynamics and their reversibility by substitution with thyroid hormones. Basic Res Cardiol 1976;71:624-44.

32 Taylor RR, Covell JW, Ross J. Influence of the thyroid state on left ventricular tension-velocity relations in the intact, sedated dog. J Clin Invest 1969;48:775-84.

33 Lien E, Aanderud S. Systolic time intervals in the evaluation of thyroid dysfunction. Acta Med Scand 1982;211:265-8.

34 Hillis WS, Bremner WF, Lawrie TDV, Thomson JA. Systolic time intervals in thyroid disease. Clin Endocrinol (Oxf) 1975;4:617-24.

35 Weissler AM, Lewis RP, Leighton RF. The systolic time intervals as a measure of ventricular performance in man. In: Yu PN, Goodwin JF, eds. Progress in cardiology. Vol 1. Philadelphia: Lea and Febinger, 1972:155-83.

36 Fouron JC, Bourgin JH, Letarte J, Dussault JH, Ducharme G, Davignon A. Cardiac dimensions and myocardial function of infants with congenital hypothyroidism. An echocardiographic study. $\mathrm{Br}$ Heart $J$ 1982;47:584-7.

37 Burns JW, Covell JW, Ross J. Mechanics of isotonic left ventricular contractions. Am J Physiol 1973; 224:725-32.

38 Quinones MA, Gaasch WH, Cole JS, Alexander JK. Echocardiographic determination of left ventricular stress-velocity relations in man. Circulation 1975;51:689-700.

39 Merillon JP, Passa Ph, Chastre J, Wolf A, Gourgon R. Left ventricular function and hyperthyroidism. $\mathrm{Br}$ Heart $J$ 1981;46:137-43. 